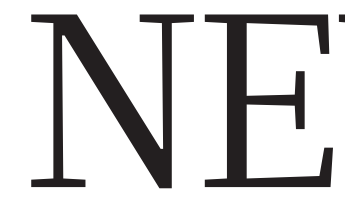

GREECE Campus protesters rally to preserve student power $\mathbf{p . 1 5}$


REPRODUCTION Egg-making stem cells might buy time for women p.16
FuNDING Budget threatens health of US disease agency $\mathbf{p . 1 9}$
PROFILE Michael Merzenich, brain-game guru, plays a new hand $\mathbf{p . 2 4}$

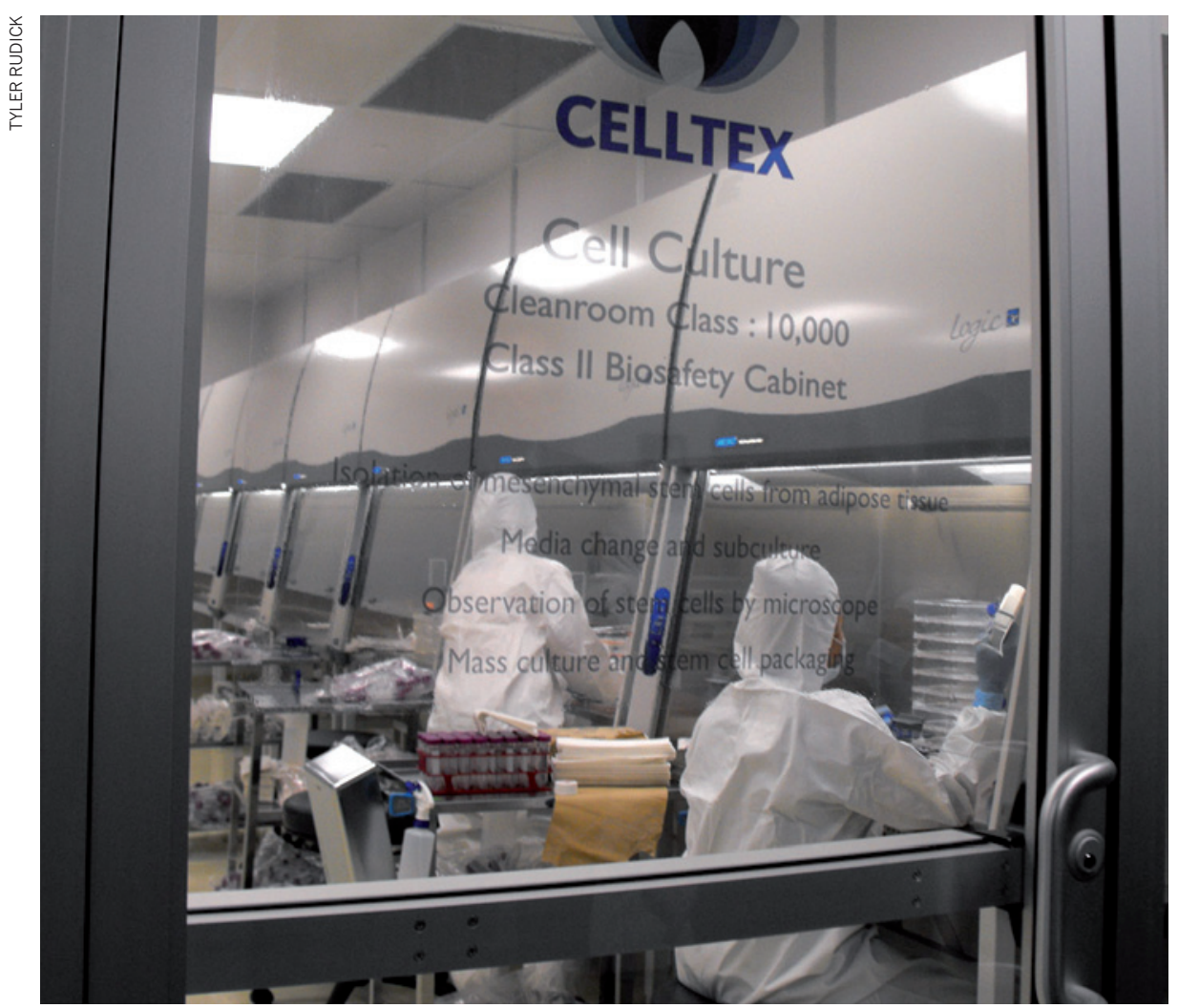

Celltex hosts the largest stem-cell bank in the United States.

REGENERATIVE MEDICINE

\title{
Stem-cell therapy takes off in Texas
}

\section{A boom in unproven procedures is worrying scientists.}

\section{BY DAVID CYRANOSKI}

$\mathrm{W}$ ith Texas pouring millions of dollars into developing adult stem-cell treatments, doctors there are already injecting paying customers with unproven preparations, supplied by an ambitious new company.

The US Food and Drug Administration (FDA) has not approved any such stem-cell treatment for routine clinical use, although it does sanction them for patients enrolled in registered clinical trials. Some advocates of the treatments argue, however, that preparations based on a patient's own cells should not be classed as drugs, and should not therefore fall under the FDA's jurisdiction.

There are certainly plenty of people eager to have the treatments. Texas governor Rick Perry, for instance, has had stem-cell injections to treat a back complaint ${ }^{1}$, and has supported legislation to help create banks to store patients' harvested stem cells.

One company that has benefited from this buoyant climate is Celltex Therapeutics, which "multiplies and banks" stem cells derived from people's abdominal fat, according to chairman and chief executive David Eller. Its facility in Sugar Land, just outside Houston, opened in December 2011 and houses the largest stem-cell bank in the United States.

Celltex was founded by Eller and Stanley Jones, the orthopaedic surgeon who performed Perry's procedure, and it uses technology licensed from RNL Bio in Seoul. Because clinical use of adult-stem-cell treatments are illegal in South Korea, RNL has since 2006 sent more than 10,000 patients to clinics in Japan and China to receive injections.

Celltex says that although it processes and banks cells, it does not carry out stem-cell injections. It declined to answer Nature's questions about whether its cells have been used in patients. But there is evidence that the company is involved in the clinical use of the cells on US soil, which the FDA has viewed as illegal in other cases.

\section{PUBLIC HYPE}

In addition to the publicity surrounding Perry's treatment, a woman named Debbie Bertrand has been blogging about her experiences during a five-injection treatment with cells prepared at Celltex. Her blog (http://debbiebertrand.blogspot.com) hosts photographs of herself alongside Jones; Jennifer Novak, a Celltex nurse; Jeong Chan Ra, chief executive of RNL Bio; and her doctor, Jamshid Lotfi, a neurologist who works for the United Neurology clinic in Houston. Another photo is captioned: "My cells are being processed in here for my next infusion!!!” A third shows Bertrand, Lotfi and a physician called Matthew Daneshmand, who is, according to the caption, injecting Bertrand's stem cells into an intravenous drip, ready for the infusion. Nature has been unable to contact Bertrand.

Lotfi says that he has administered cells processed by Celltex to more than 20 people. "Five or six" - including Bertrand - have multiple sclerosis and "four or five" have Parkinson's disease, he says. Lotfi explains that patients sign up for treatment by contacting Novak, and that cells are prepared by removing about five grams of fat - containing roughly 100,000 mesenchymal stem 
- cells - from the patient's abdomen. Over a three-week period, the cells are cultured until they reach about 800 million cells. Lotfi says that patients get at least three injections of 200 million cells each, and that the cells do not take effect for a few months. According to Lotfi, Celltex charges US\$7,000 per 200 million cells, and pays Lotfi $\$ 500$ per injection.

Lotfi says that most of his patients claim to get better after the treatment, but he admits that there is no scientific evidence that the cells are effective. "The scientific mind is not convinced by anecdotal evidence," he acknowledges. "You need a controlled, double-blind study. But for many treatments, that's not possible. It would take years, and some patients don't have years."

"The worst-case scenario is that it won't work," he adds. "But it could be a panacea, from cosmetics to cancer." He says that Celltex is conducting a trial in which patients "will be their own control". "If you can compare before and after and show improvement, there's no need for a placebo," he explains. "How can you charge people, and then give them a placebo?"

\section{STANDARD PRACTICE}

The answer, according to most biomedical researchers, is to follow the normal strategy for an unproven medicine: conduct a placebocontrolled clinical trial in which patients are not charged. "This is crucial for clinical trials to yield meaningful data and to avoid the placebo effect," says Joshua Hare, director of the Interdisciplinary Stem Cell Institute at the University of Miami in Florida, who worked with the biotechnology company Osiris Therapeutics in Columbia, Maryland, to conduct a trial of adult mesenchymal stem cells in patients who have had a heart attack ${ }^{2}$.

The FDA does exempt some "compassionate use" procedures from these requirements, but only for very small numbers of patients with life-threatening disorders that demand immediate intervention.

Eller says that Celltex has "initiated a programme of clinical research" that has been approved by an independent review board in Texas and is designed to meet the standards set by the International Society for Stem Cell Research (ISSCR) in Deerfield, Illinois. "Our clinical trials are led by physician investigators who have completed training in both the

use of autologous mesenchymal stem cells and in research ethics," he explains. But he would not say whether the trials had started or been approved by the FDA, nor who would run them, what disorders would be targeted or whether patients would be charged. Meanwhile, RNL has published a phase I trial showing that its treatment for spinal-cord injury is safe ${ }^{3}$, and plans a phase II trial in South Korea to establish efficacy. It has also applied to the FDA to conduct a clinical trial in the United States.

Stem-cell scientists contacted by Nature are concerned by Celltex's activity. "Because we know so little about mesenchymal stem cells and whether they are indeed effective for

\section{"The scientific mind is not convinced by anecdotal evidence."} treating any condition, I'd be very wary of how they are being infused into patients, and certainly concerned if practitioners are charging patients for medical procedures that haven't been proven to work and could in fact be harmful," says George Daley, director of the Stem Cell Transplantation Program at Harvard Medical School in Boston, Massachusetts, who helped the ISSCR to draft its guidelines. In the opinion of Arnold Kriegstein, director of the Eli and Edythe Broad Center of Regeneration Medicine and Stem Cell Research at the University of California, San Francisco, "the very nature of Celltex's business plan, which involves charging patients considerable fees for socalled treatments for diseases and disorders for which there is no good clinical evidence of efficacy, crosses an ethical line".

Celltex recently brought in Glenn McGee, the editor-in-chief of the American Journal of Bioethics, to be its first president for ethics and strategic initiatives ${ }^{4}$. "I am working to build a programme of Celltex-run clinical trials that exceed the ethical standards promulgated by the best document to date on the matter, that from the ISSCR," says McGee. However, like Eller, McGee declined to answer Nature's questions about the company's knowledge of or involvement in the clinical use of its stem cells, nor would he talk about the legality and ethical nature of such practices.

The legal standing of stem-cell treatments is currently being debated in a court case brought by Regenerative Sciences of Broomfield, Colorado, which was ordered by the FDA in 2010 to stop administering mesenchymal stem cells to patients ${ }^{5}$. One of the key issues being debated is whether the cells are "minimally manipulated" before being reinjected into the patient. Treatment with the patient's own, unprocessed tissue does not always require FDA approval.

\section{DEGREE OF MANIPULATION}

In a previous version of his LinkedIn profile, McGee asserted that Celltex "minimally modified" its cells. But Rita Chappelle, a spokeswoman for the FDA's Center for Biologics Evaluation and Research in Silver Spring, Maryland, contends that any "expanded" cells cannot be considered minimally manipulated. Another source, who used to work for the FDA's cellular therapy division and requested anonymity because they now work in the private sector, says that any cells kept outside the body overnight before injection are considered more than minimally manipulated.

The Texas Medical Board, which regulates physicians in the state, has now stepped into the fray. On 10 February, it approved draft rules that will require physicians to gain approval from an independent review committee before treating patients with adult stem cells. This stipulation, expected to become law in April, is meant to ensure patient safety and give physicians "a reasonable and responsible degree of latitude in the kinds of therapies they offer their patients", the draft rule says.

But Douglas Sipp, an expert in stem-cell regulations and ethics at the RIKEN Center for Developmental Biology in Kobe, Japan, believes that the Texas Medical Board is merely delegating the regulation of adultstem-cell treatments to local review boards, which have little accountability, when the responsibility should lie with the FDA.

It is also unclear how Celltex will be affected by the rules. Lotfi, for one, does not think that they will hamper his treatments greatly. "It will be just a little more red tape,"he says. — SEE EDITORIAL P.5

1. Cyranoski, D. Nature 477, 377-378 (2011).

2. Hare, J. H. et al. J. Am. Coll. Cardiol. 54, 2277-2286 (2009).

3. Ra, J. C. et al. Stem Cells Dev. 20, 1297-1308 (2011).

4. Cyranoski, D. Nature 482, 449-450 (2012)

5. Cyranoski, D. Nature 466, 909 (2010).

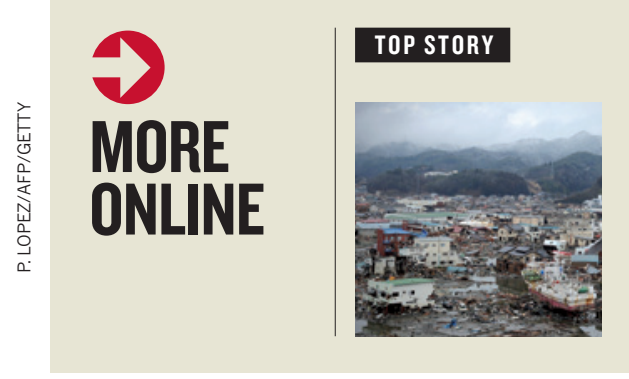

Scientists report back from Fukushima exclusion zone go.nature.com/ w3gvft

\section{MORE NEWS}

- Optical memory could ease Internet bottlenecks go.nature.com/libuga

- Researchers chart intellectual trends in arXiv go.nature.com/uq11tl - Budget cuts force lay-offs at UN biotechnology centre go.nature.com/h7wrnp

\section{PODCAST}

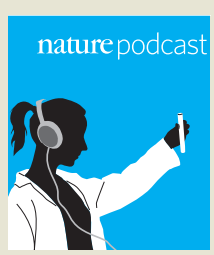

Patterns of human movement, exploring a fossil forest, and who really deciphered hieroglyphs? go.nature.com/w5vqad 